\title{
Kytococcus sedentarius
}

National Cancer Institute

\section{Source}

National Cancer Institute. Kytococcus sedentarius. NCI Thesaurus. Code C86473.

A species of aerobic, Gram positive, cocci shaped bacteria assigned to the phylum Actinobacteria. This species is nonencapsulated, nonendosporeforming, nonmotile, catalase positive, oxidase negative and hydrolyzes gelatin. K. sedentarius is rarely part of the normal flora of the skin and is mostly pathogenic, being the causative agent of pitted keratolysis. 